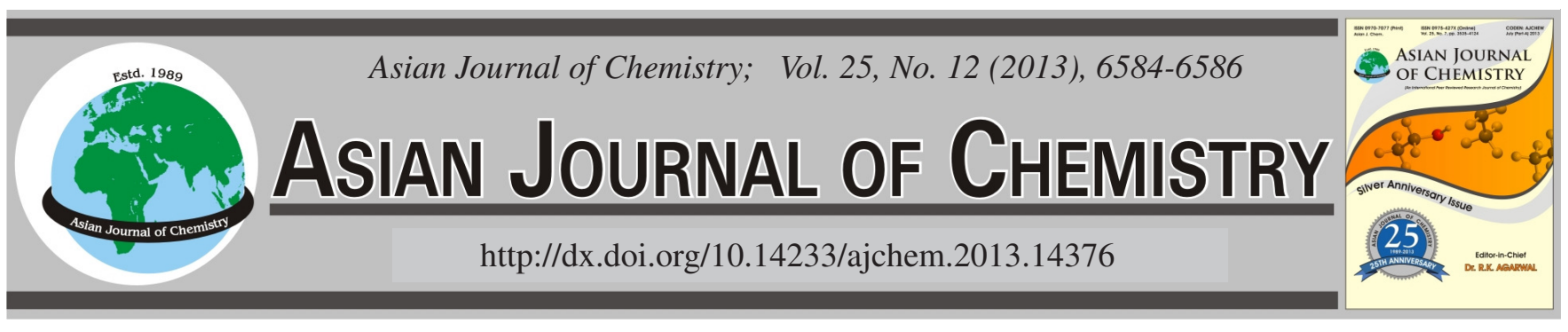

\title{
Alkaloid Profiling of Conventionally Propagated and in vitro Raised Plants of Indian Snake Plant (Rauwolfia serpentina L.)
}

\author{
Subhadra R. Mallick ${ }^{1}$, Priyadarsani Samal ${ }^{1}$, Ram C. Jena ${ }^{2}$ and Kailash C. Samal, ${ }^{1, *}$
}

${ }^{1}$ Department of Agricultural Biotechnology, Orissa University of Agriculture and Technology, Bhubaneswar-751 003, India ${ }^{2}$ DNA Fingerprinting Laboratory, Biotechnology-cum-Commercial Tissue Culture Centre, Odisha University of Agriculture and Technology, Bhubaneswar-751 003, India

*Corresponding author: E-mail: samalkc@ rediffmail.com

\begin{abstract}
The present investigation was carried to investigate alkaloid profiling of a woody perennial medicinal plant 'sarpagandha' (Rauwolfia serpentina L.) propagated through conventional method as well as in vitro condition. The crude alkaloid fraction was estimated highest in roots of in vitro grown plants ( $487 \mathrm{mg} \mathrm{g}^{-1} \mathrm{dry} \mathrm{wt}$ ) followed by roots of conventionally propagated plant $\left(457 \mathrm{mg} \mathrm{g}^{-1} \mathrm{dry}\right.$ wt). The lowest

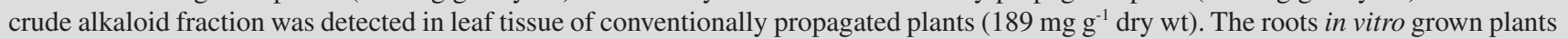
and conventionally propagated plants had higher crude alkaloid fraction than other parts of the plants. The thin layered chromatography analysis of all the samples, including roots, leaves and callus, showed that roots are rich in reserpine and they also contain other alkaloids besides reserpine. Callus tissues also contain reserpine as well as other alkaloids, but the other alkaloids could not be detected in the leave samples. But HP-thin layered chromatography analysis could able to detect the reserpine and other alkaloid in all samples. The alkaloid profiling through HP-TLC detected a number of alkaloids from all the plant samples. The highest reserpine content was obtained from the in vitro regenerated roots $\left(35.27 \mathrm{mg} \mathrm{g}^{-1}\right)$ and the least reserpine $\left(8.54 \mathrm{mg} \mathrm{g}^{-1}\right)$ was observed from the leaves conventionally propagated plants.
\end{abstract}

Key Words: Alkaloid, In vitro culture, HP-TLC, Rauwolfia serpentina, Reserpine.

\section{INTRODUCTION}

Rauwolfia serpentina L. Benth. ex. Kurz (family: Apocynaceae) is a woody perennial erect shrub, commonly known with different names; 'sarpagandha', 'snake root plant', 'chotachand', 'chandrika' etc. Its roots are tuberous with pale brown cork which has been used in Ayurvedic medicines under the name 'sarpagandha' and 'nakuli' for the treatment of mental disorders. It has been used for centuries for the relief of various central nervous system disorders, both psychic and motor, including anxiety states, excitement, maniacal behaviour associated with psychosis, schizophrenia, insanity, insomnia and epilepsy. Extracts of the roots are valued for the treatment of intestinal disorders, particularly diarrhea and dysentery. Mixed with other plant extracts, they have been used in the treatment of cholera, colic and fever. It is also used as a febrifuge and as an antidote to the bites of poisonous reptiles like snakes. Its medicinal value has been accepted by the allopathic system $^{1,2}$.

Reserpine is the most important alkaloid present in root, stem and leaves of the plant which varies from 1.7 to $3.0 \%$. The root barks has more than $90 \%$ of the total alkaloids in roots. The percentage of the alkaloid depends on the geogra- phical place from where the plant is collected and also the season of collection. Generally samples from Assam have a higher percentage of alkaloids $(2.57 \%)$ than the other parts of India and December is the best month for the collection for getting more percentage of alkaloids. But, age of the plant has no effect on the percentage of alkaloid content (up to 4 years). Ajmalicine, ajmaline, isoajmaline, ajmalinine, chandrine, rauwolfinine, renoxidine, rescin-namine, reserpiline, reserpin, reserpinine, sarpagine, serpentine, serpentinine, tetraphyllicine, yohimbin etc are the different alkaloids present in root of this plant. In 1952, an U.S. physician named Wilkins demonstrated the positive effects of reserpine, one of 50 isolated from the root, was to revolutionize the treatment of mental illness and high blood pressure by the western medical.

Its natural source is now almost exhausted due to indiscriminate recurrent harvest and other anthorpogenic pressure and activities. In Odisha it is now mainly confined to some virgin valleys and hilly forest tracks. For the fulfillment of the present and future demand this plant needs to be cultivated scientifically at a commercial scale. But its cultivation through seeds is difficult due to low germination \% for different structural and physiological reasons. Seed germination 15-20\% 
but only $10-13 \%$ plant development from the germinated seeds of $R$. serpentine was observed ${ }^{3}$. Seed germination of $R$. serpentina was quite erratic, ranged from $8-48 \%$ with an average of $19 \%$. To cope up with alarming situation, plant tissue culture technique has come as a boon. In this method, explants such as nodal segments, auxiliary bud, shoot meristem are sub-cultured in tissue culture medium supplemented with growth regulators cytokinin and or auxin and cytokinin combinations to produce multiple shoots. Shoot number increases logarithmically with each subculture to give greatly enhanced multiplication rates. As this method involves only organized meristem, hence it allows recovery of genetically stable and true to type progenies. The objective of the present study is to compare the alkaloid content of in vitro raised plants with conventionally propagated plants.

\section{EXPERIMENTAL}

The Rauwolfia plants were grown in the medicinal plant garden of Orissa University of Agriculture and Technology, Bhubaneswar, India during the year (2008-11) by adopting conventional method of propagation (from seeds). Also Rauwolfia plants were raised under in vitro condition from excised shoot tip explants by multiple shoot induction in Murashige and Skoog medium ${ }^{5}$ and subsequent rooting and hardening. After hardening, these in vitro raised plants were further planted in the medicinal garden.

Alkaloid extraction: The roots and leaves were collected from both conventionally propagated and in vitro raised plants and washed with running tap water for $0.5 \mathrm{~h}$. Similarly, the calli formed from the shoot tip explant cultured in vitro condition on MS medium supplemented with $2.5 \mathrm{mg} / \mathrm{L} \mathrm{2,4-D} \mathrm{were}$ also used for extraction of different alkaloid. A known amount of roots, leaves and calli (100 g each) were kept in an oven at $40{ }^{\circ} \mathrm{C}$ for drying to constant weight. The dried roots, leaves and calli were powdered in a mixer-grinder and used for the study. The dried plant powdered materials of different parts (leaf, root and callus) of in vitro and conventionally propagated plants were separately extracted with ethanol. The solvent was evaporated under reduced pressure at $40^{\circ} \mathrm{C}$ in a rotary evaporator to obtain brownish to blackish green residues. Each crude extract was suspended into water and extracted with petroleum ether $(50 \mathrm{~mL})$ using a separating funnel to remove pigments and fatty substances. The organic solvents were combined and evaporated under reduced pressure to obtain greenish masses in each case of plant materials. Then the aqueous layer was separated and extracted with chloroform $(50 \mathrm{~mL})$ and the solvent was evaporated under reduced.

Pressure to obtain neutral chloroform extracts: The residual aqueous layer was made acidic $(\mathrm{pH} 3.0)$ by adding $1 \mathrm{~N} \mathrm{HCl}$ and extracted with chloroform $(50 \mathrm{~mL})$ and the solvent was evaporated under reduced pressure to afford acidic chloroform extract. The remaining acidic aqueous was made alkaline ( $\mathrm{pH} 9.0)$ by adding $\mathrm{NH}_{4} \mathrm{OH}$ solution and again extracted with $(50 \mathrm{~mL})$ and the solvent was evaporated under reduced pressure to obtain basic chloroform extract. All chloroform extracts were tested for alkaloid using Dragendroff's reagent. The chloroform extracts thus obtained were combined and subjected to a column chromatography with silica gel (60 mesh) and eluded with chloroform, chloroform-methanol with increasing polarity. The fractions that showed the presence of alkaloid in thin layered chromatography (TLC) were combined together and solvent was evaporated under reduced pressure to obtain crude alkaloid mixture.

Alkaloid separation and profiling: The crude alkaloid mixture was subjected to thin layer chromatography (TLC) and spotted on TLC-pre-coated silica gel plate. Each plate contains samples and two standards of reserpine and recinnamine (purchased from Hi-media Laboratories) dissolved in methanol $\left(1.0 \mathrm{~g} \mathrm{~mL}^{-1}\right)$. The mobile phase was chloroform $\left(\mathrm{CHCl}_{3}\right)$ and methanol $\left(\mathrm{CH}_{3} \mathrm{OH}\right)$ in 97:3 ratio (v/v) or chloroform, methanol and aqueous ammonia $\left(\mathrm{NH}_{3}\right)$ in 95:4.5:0.5 (v/v/v) ratio. Spots were visualized by the spray of Dragendorff 's reagent. The sprayed plates develop orange spots. Spots intensify if the plates further sprayed with $\mathrm{HCl}$, or $50 \%$ water-phosphoric acid and finally the $\mathrm{R}_{\mathrm{f}}$ value was calculated.

For better separation of alkaloids, the HP-TLC techniques were adopted. The readymade HP-TLC plates (Silica $60, \mathrm{~F}_{254}$, $20 \times 20 \mathrm{~cm}$ ) were visualized in UV chamber prior to use for ensuring the clearness of plates. The sample extracts from different plant parts were loaded (1.2 $\mu \mathrm{L}$ per spot) on the plates with the help of in-built sample loader. After loading the sample, plates were placed into saturated TLC chamber containing the mobile phase $\mathrm{CHCl}_{3}: \mathrm{CH}_{3} \mathrm{OH}(97: 3 \mathrm{v} / \mathrm{v})$. Thereafter, plates were taken out and solvent front was marked and then plates were dried in the oven. After drying, plates were visualized in UV-chamber and scanned by CMAG TLC scanner at 200-700 $\mathrm{nm}$ and different spectral pattern and peaks were observed.

Data analysis: All data were analyzed by SAS v. 8.0. Analysis of variance (ANOVA) was used to test the statistical significance $^{6}$. The difference between significant treatments means were tested using Dunkan's multiple range test at $5 \%$ $(\mathrm{p} \leq 0.05)$.

\section{RESULTS AND DISCUSSION}

The crude alkaloid fraction differed significantly among the different plant parts of conventionally propagated and in vitro raised plants. The comparison of the alkaloid content between different parts (callus, root, leaf) of the in vitro and conventionally propagated plant parts (leaf and root) was presented in (Table-1). The crude alkaloid fraction was estimated highest in roots of in vitro grown plants (487 $\mathrm{mg} \mathrm{g}^{-1}$ dry wt) followed by roots of conventionally propagated plant $(457 \mathrm{mg}$ $\mathrm{g}^{-1}$ dry wt). The lowest crude alkaloid fraction was detected in leaf tissue of conventionally propagated plants $\left(189 \mathrm{mg} \mathrm{g}^{-1}\right.$ dry wt. The roots in vitro grown plants and conventionally propagated plants had higher crude alkaloid fraction than other parts of the plants. But as compared to the roots of conventionally propagated plants the in vitro raised plants exhibited higher crude alkaloid fraction.

Moreover, the production of secondary metabolites can also be controlled by controlling different factors. That is why it should be quoted that manipulation of cultural conditions and composition of growth factors induced a variation in alkaloid biosynthesis both by callus culture and regenerated plants ${ }^{7}$. The type, number and quality of chemical substances present in medicinal plants are dependent upon soil, climate, 
season, nature and intensity of light, day length, stage of growth plant $e t c^{8}$. The medicinal quality of plant or its parts therefore, varies from sample to sample due to variation in above (one or more) factors. But it is more or less constant in vitro grown plant materials as they are maintained and controlled in sophisticated conditions.

TABLE-1

TOTAL ALKALOID ISOLATED FROM IN VITRO

RAISED AND CONVENTIONALLY PROPAGATED PLANTS OF RAUWOLFIA SERPENTIN

\begin{tabular}{lcc}
\hline Source & Plant material & $\begin{array}{c}\text { Crude alkaloid fraction } \\
\left(\mathrm{mg} \mathrm{g}^{-1} \text { dry wt }\right)\end{array}$ \\
\hline In vitro & Callus & $245^{\mathrm{c}}$ \\
& Root & $487^{\mathrm{a}}$ \\
Field grown & Leaf & $234^{\mathrm{c}}$ \\
& Leaf & $189^{\mathrm{d}}$ \\
& Root & $453^{\mathrm{b}}$ \\
\hline
\end{tabular}

*Mean values followed by similar letters are non-significant at $p=$ 0.05 , CAF: Crude alkaloid fraction

Alkaloid profiling: The alkaloid profile of different plant parts of $R$. serpentina were qualitatively observed by separating the alkaloid fraction in thin layered chromatography (Table2). $R_{\mathrm{f}}$ (retardation factor) values of reserpine was estimated to be 0.96 . From the alkaloid profile of different plant parts of $R$. serpentina, it was revealed that all the root and callus samples contain reserpine. The root and callus samples also contain alkaloids other than reserpine whose $R_{f}$ values range between $0.45-0.48$. The alkaloids other than reserpine were not detected in all the leave samples.

\begin{tabular}{lccc}
\multicolumn{5}{c}{ TABLE-2 } \\
QUALITATIVE ESTIMATION OF RESERPINE IN THE \\
DIFFERENT PLANT PARTS OF IN VITRO RAISED AND \\
CONVENTIONALLY PROPAGATED PLANTS OF \\
\multicolumn{4}{c}{ RAUWOLFIA SERPENTINA BY TLC } \\
\hline Source & Plant material & Reserpine & Others \\
\hline In vitro & Callus & + & + \\
& Root & + & + \\
Field grown & Leaf & + & - \\
& Leaf & + & - \\
\hline
\end{tabular}

*The $\mathrm{R}_{\mathrm{f}}$ values for reserpine (0.96)

Similarly, the alkaloid profiling of all the plant samples, including roots, leaves and callus of $R$. serpentina was done by HP-TLC. The alkaloid profile exhibited a great deal of variation in the number of alkaloids in each plant samples and 2-7 alkaloids were detected in all tissues analyzed. The alkaloid profile of root samples showed that roots are rich in reserpine content (Table-3). In addition they also contain other alkaloids. The roots of in vitro raised plants contain higher amounts of reserpine $\left(35.27 \mathrm{mg} \mathrm{g}^{-1}\right.$ ) than the conventional propagated plants (23.44 $\mathrm{mg} \mathrm{g}^{-1}$ ) which corroborate the earlier findings 9 . Alkaloid profile of the calli regenerated in MS medium also contains reserpine content. The alkaloid profile of leaf samples of conventional propagated plants showed the least content of reserpine $\left(8.54 \mathrm{mg} \mathrm{g}^{-1}\right)$. The alkaloid profiling of different plant samples envisages that the production of secondary metabolites by plants depends greatly on the physiological and developmental stages of the plants. The synthetic capacity of de-differentiated tissue often differs substantially from that of fully differentiated tissues, both qualitatively and quantitatively, because of differences in the enzyme profiles which regulate the organ-specific expression of the biosynthetic genes. The differentiated cultures often show biochemical and genetic stability and hence, offers a predictable and high-productivity system which does not require extensive optimization ${ }^{10}$. The biosynthesis usually occurs in an organ in a tissue-specific manner and is often temporally restricted during the development ${ }^{11-13}$.

\begin{tabular}{ccc}
\multicolumn{3}{c}{ TABLE-3 } \\
\multicolumn{3}{c}{ RESERPINE CONTENT IN DIFFERENT PLANT SAMPLES OF } \\
\multicolumn{2}{c}{ R. SERPENTINA L. QUANTIFIED THROUGH HP-TLC } \\
\hline Source & Plant material & Reserpine CAF mg g-1 DW \\
\hline In vitro & Callus & $18.74^{\mathrm{b}}$ \\
& Root & $35.27^{\mathrm{d}}$ \\
Field grown & Leaf & $10.87^{\mathrm{a}}$ \\
& Leaf & $8.54^{\mathrm{a}}$ \\
& Root & $23.44^{\mathrm{c}}$ \\
\hline **Mean values followed by similar letters are non-significant at $\mathrm{p}=$ \\
0.05; The $\mathrm{R}_{\mathrm{f}}$ values for Reserpine $(0.25)$, CAF: Crude alkaloid fraction
\end{tabular}

\section{Conclusion}

In essence, the present study describes alkaloid profiling of conventionally propagated and in vitro raised plants of Rauwolfia serpentina. The alkaloid content was found higher in roots, leaves of in vitro raised plants. This finding will considerably encourage better adoption of in vitro raised plants and that will help large scale cultivation of this endangered plant and production of essential alkaloid for therapeutic use.

\section{ACKNOWLEDGEMENTS}

The authors are grateful to Department of Biotechnology, Ministry of Science and Technology, Government of India, New Delhi, India for financial support.

\section{REFERENCES}

1. J. Ojha and U. Mishra, Dhanvantari Nighantuh, with Hindi Translation and Commentary, Ist ed. Deptt. Of Dravyaguna, Institute of Medical Sciences, Banaras Hindu University, Varanasi, India, p. 204 (1985).

2. R.J. Vakil, Br. Heart J., 11, 350 (1949).

3. K.N.R. Nair, Ind. Forester, 81, 168 (1955).

4. S. Hedayatullah, J. Sci. Ind. Res., 2, 118 (1959).

5. T.S. Murashige and F. Skoog, Physiol. Plant, 15, 473 (1962).

6. V.G. Panse and P.V. Sukhatme, Statistical Methods for Agricultural Workers, Indian Council of Agricultural Research, New Delhi, India, p. 381 (1967).

7. I. Illahi, Proceedings of the International Plant Tissue Culture Conference, Dhaka, Dec. 19-21, pp. 21-21 (1993).

8. A. Ghani Medicinal Plants of Bangladesh-Chemical constituents and uses, Council of Scientific and Industrial Research, Dhaka, Bangladesh, p. 72 (1998).

9. C.M. Ruyter, M. Akram, I. Illahi and J. Stockigt, Planta Med., 57, 328 (1991).

10. R.A. Dixon, Nature, 411, 843 (2001).

11. T. Hartmann, Entomol. Gen. Appl., 80, 177 (1996).

12. W.G.W. Kurz and F. Constabel, in eds.: A. Altman, Production of Secondary Metabolites. Agricultural Biotechnology, Marcel Dekker Inc., New York, USA, pp. 183-224 (1998).

13. K.M.O. Caldentey and D. Inze, Trends Plant Sci., 9, 433 (2004). 